http://jmscr.igmpublication.org/home/ ISSN (e)-2347-176x ISSN (p) 2455-0450

crossref DOI: https://dx.doi.org/10.18535/jmscr/v8i4.21

\title{
Comparative Study of Effects of Phenylephrine and Mephenteramine on APGAR Scores of Babies Born by Caesarion Section
}

\author{
Authors \\ Dr Mary Mammen DNB ${ }^{{ }^{*}}$, DR. Marina Rajan $\mathrm{MD}^{2}$ \\ ${ }^{1}$ Assistant Professor, Dept. of Anesthesiology, Pushpagiri Institute of Medical Sciences, Thiruvalla, Kerala, \\ India \\ ${ }^{2}$ Professor of community Health, Believers Church Medical College Thiruvalla \\ *Corresponding Author \\ Dr Mary Mammen DNB \\ Chempakasseril, RSPO, Thiruvalla, Kerala, 689111, India
}

\begin{abstract}
Neonatal outcome after birth is assessed by APGAR SCORE at lminute and 5 minutes of birth. It evaluates the need for active resuscitation of the babies. Maternal blood pressure, sedative drugs given to the mother, gestational age, congenital malformation of babies, are all factors affecting APGAR SCORE of neonates. Most of the caesarian sections are done under spinal anaesthesia which will cause hypotension due to sympathetic block. Vasopressors like mephenteramine and ephedrine are commonly used to elevate hemodynamic status of the mother. APGAR SCORE of the babies were well maintained with these drugs. We used prophylactic intravenous phenylephrine 100ugms and IV Mephenteramine $6 m g m$ to alleviate the hypotension and observed the APGAR score of the babies born to these mothers who underwent caesarian section under spinal anaesthesia at lminute and 5 minutes after birth.

Keywords: APGAR score, Caesarian section, Spinal anaesthesia, Hypotension, Phenylephrine and Mephenteramine.
\end{abstract}

\section{Introduction}

Most of the caesarian sections are done under spinal anaesthesia. More than $80 \%$ of full term pregnant subjects experience hypotension after spinal anaesthesia. More than $20 \%$ fall in blood pressure from the baseline value is deleterious to both mother and baby under spinal anaesthesia. Hypotension is exaggerated by compression of inferior venacava and aorta by the gravid uterus in supine position by decreasing the venous return $^{[14]}$. Common vasopressors used to alleviate this hypotension are ephedrine, mephenteramine and metarminol. Phenylephrine, a pure alpha 2 agonist was not popular in the early days ${ }^{[3]}$.
Neonatal outcome is basically assessed by APGAR SCORE at 1 minute and 5 minutes after delivery. Blood analysis of umbilical artery and continuation of APGAR score every 5 minutes also helps in the progressive assessment of the neonates.

APGAR Score was devised by Dr Virginia Apgar in $1952^{(1)}$. It evaluates the need for active resuscitation $^{[13]}$ applied at 1 minute and 5 minutes after birth. Assessment is based on appearance, pulse, grimace, activity, and respiratory rate [effort]. Appearence is assessed by colour [pink/blue]. Pulse is palpated at the base of umbilical artery. Muscle tone is measured by 
applying pressure to infants limbs and reflex irritability noted by stimulating the sole. In general APGAR Score of 7 and above is good ${ }^{[1]}$.

Normal uterine blood flow is $700 \mathrm{ml} / \mathrm{mt}$. There is no autoregulation. Uterine arterial pressure depends on maternal blood pressure. Maternal hypotension decreases uteroplacental blood flow and leads to foetal hypoxia. Foetal $\mathrm{pH}$ is usually higher than that of the mother's. Placental transfer of drugs depends on liver metabolism, placental hormones, foetomaternal circulation and physicochemical properties of the drug ${ }^{[3]}$. Scanlon in 1974 found that Bupivocaine the local anaesthetic used to give spinal anaesthesia caused least depressive effect on the foetus. The choice of local anaesthetic for spinal anaesthesia here is none other than $0.5 \%$ Bupiviccaine [Heavy]. Maternal sedation, gestational age, congenital malformation of the babies also influence APGAR score of neonates.

\section{Objectives}

1) To assess neonate at 1 minute and 5 minutes of birth of fullterm mothers who received prophylactic

2) Vasopressor phenylephrine during caesarian section under spinal anaesthesia

3) To assess the neonates at 1 minute and 5 minute of birth of fullterm mothers who received prophylactic vasopressor mephenteramine during caesarian section under spinal anaesthesia.

4) To compare the APGAR Score at $1 \mathrm{mt}$ and $5 \mathrm{mt}$ to evaluate any foetal hypoxia between vasopressors phenylephrine and mephenteramine.

\section{Methodology}

Study Design: This is a randomized prospective study on babies born of full term pregnant mothers aged between 18 to 40 years, weighing less than $70 \mathrm{~kg}$.

Sample Size: Sample size is calculated using the formula $n=[\mathrm{sd}] 2$ [zalpha+zbeta] 2 divided by delta square applying to similar studies. ${ }^{[10]}$
Sampling Method: BY block randomization and allocation concealed by sealed envelope.

Ethical Clearence: Permission from institutional ethical committee was obtained. A written and informed consent was obtained from each patient prior enrolling them.

Procedure: Full term pregnant mothers aged between 18 years to 40 years weighing less than $70 \mathrm{~kg}$ were chosen for this study. Both elective and caesarian section were considered. All our pregnant subjects belonged to ASA1 category. Subjects were randomly grouped into 2 groups of 30 each. All our elective subjects received antiaspiration prophylaxis Tab. Ranitidine $150 \mathrm{mgm}$ and Tab. Metaclopropamide $10 \mathrm{mgm}$ by mouth 2 hours before anaesthesia. All our emergency subjects received Inj.Ranitidine 50mgm and inj. Metaclopropamide $10 \mathrm{mgm}$ iv 30 minutes before anaesthesia. All our subjects received $500 \mathrm{ml}$ crystalloid solution on nondominant hand through $18 \mathrm{~g}$ iv canula. All our subjects were monitored with an ECG, NIBP, and SPo2 monitors. Baseline parameters were recorded and subjects were positioned laterally. All our our subjects received $1.6 \mathrm{ml}$ of $0.5 \%$ Bupivocaine [Heavy] at L3 - L4 space using $23 \mathrm{~g}$ new spinal needle. All our subjects received $100 \%$ oxygen by Bains circuit and a left lateral lift was given by a wedge under right buttocks. Group 1 received 100microgram phenylephrine and group 2 received $6 \mathrm{mgm}$ Mephenteramine intravenously as prophylactic vasopressor along with spinal anaesthesia. Apgar score of the babies at 1 minute and 5 minute were noted.

\section{Results}

APGAR score of 4 babies in group 1 was 7 at 1 minute and 9 at 5minutes. In group 2 all the babies showed an APGAR score of 9 at 1 minute and 5 minutes. 


\section{Table 1}

Mean APGAR Score of babies born to full term pregnant mothers after caesarian section under spinal anaesthesia in Group 1 and Group 2 at 1 and 5 minutes

\begin{tabular}{|l|c|c|}
\hline APGAR Score & Group 1 & Group 2 \\
\hline $1 \mathrm{~min}$ & 8.7 & 8.1 \\
\hline $5 \mathrm{~min}$ & 9.0 & 9.0 \\
\hline
\end{tabular}

As seen in the above table all the group 1 babies achieved APGAR 9 at the end of 5 minutes. They did not require any additional active resuscitation.

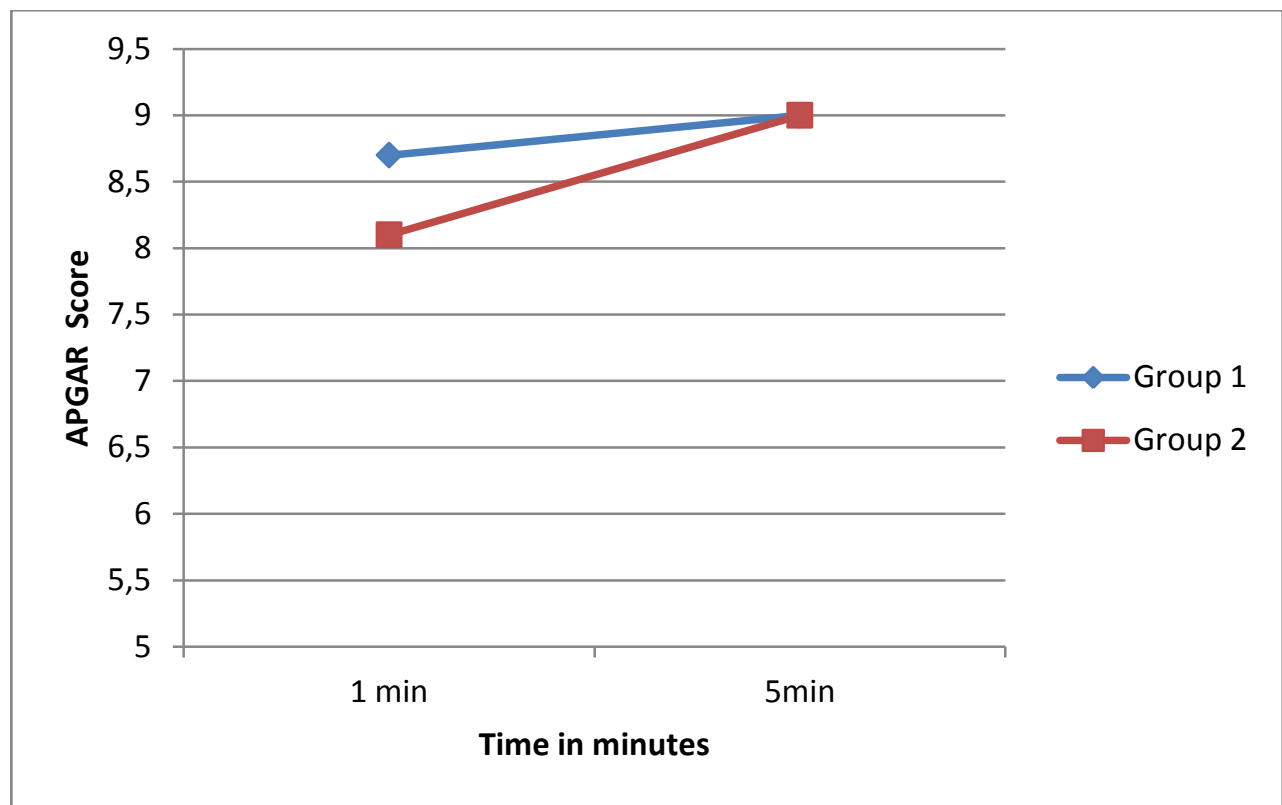

Figure 1 Change in Apgar Score of babies born to full term mothers who received prophylactic vasopressors during caesarian section under spinal anaesthesia in group1 and group 2. Graphical representation.

Table 3 Stastical Representation

Mann Whitney test shows $\mathrm{P}$ value more than 0.05 . Hence it is concluded that there is no statistically significant difference in foetal outcome between group1 and group2 babies.

\begin{tabular}{|l|c|c|}
\hline Test Statistics & APGAR at 1 min & APGAR at 5 min \\
\hline Mann Whitney $\mu$ & 403.000 & 450.000 \\
\hline Wilcoxou W & 868.000 & 915.000 \\
\hline Z & -1.450 & 0.000 \\
\hline Asym Sig 2 tailed & 0.147 & 1.00 \\
\hline
\end{tabular}

\section{Discussion}

As shown in the results (Table1 and Table 2) this study documents that phenylephrine when used for mothers undergoing caesarian section under spinal anaesthesia does not affect foetal outcome. Mohta $\mathrm{M}$ et al ${ }^{[14]}$ state that mephenteramine does not cause any adverse effects on the neonate assessed by blood gas studies and Apgar score observations. As shown above in our results all the neonates in group $2 \mathrm{had}$ an Apgar score of 9 at 1 minute and 5 minutes.
Greiss et al showed in pregnant ewes that pure alpha agonist should be avoided in obstretic anaesthesia $^{(3)}$. But David Cooper et $\mathrm{al}^{[5]}$ in his study showed that foetal acidosis was less frequent in phenylephrine [ $p=0.004,1 / 48]$. Gihan et $\mathrm{al}^{[4]}$ in his study also did not notice any significant difference in neonatal data which includes umbilical cord venous $\mathrm{pH}$ and APGAR Score at 1 minute and 5 minutes. Ramanathan ${ }^{[6]}$ and Moron $^{[7]}$ also did not notice any adverse effects on the baby when phenylephrine was used 
as a vaso pressor ${ }^{[8]}$. Chandrakala $\mathrm{P}$ Gunda et al in their study had noted an APGAR score between 8 and $9^{[9]}$ at 1 minute and 5 miniutes.

${ }^{[9]}$ Warwick D Ngan kee also had noted an APGAR Score at 1 minute and 5 minutes greater than 7 and also states that foetal acidosis is less in phenylephrine group. Though we couldn't analyse umbilical blood ph in our babies because of difficult accessibility to blood analysis at the time of our studies, all neonates in phenylephrine group did well after 5 minutes and none of them needed active resuscitation proving the safety of phenylephrine as a prophylactic vasopressor in spinal anaesthesia for caesarian section on foetus ${ }^{[10,11]}$. We have excluded foetal distress, umbilical cord prolapse, preterm pregnancy, and avoided babies with congenital problems. All our mothers belonged to ASA 1. None of them received any sedation till the baby was out.

\section{Conclusion}

Phenylephrine when given as a prophylactic vasopressor in spinal anaesthesia for ceasarian section is safe and it maintains a good APGAR Score at $5 \mathrm{mts}$ similar to Mephenteramine.

\section{References}

1. American Academy of Paediatrics Committee on foetus and Newborn and American College of obstetrecian and gynecology,

Paediatrics.October2015:136[4]819-822;

Dol:http://doi.org/10.1542/peds2015-2651.

2. Scalon. J.W., Brow W.U., Weiss J B. Neurobehavioural response of newborn infants after epidural anaesthesia. Anaesthesiology 1974;40:121-8

3. Greiss F C,Crandell D L. Therapy for hypotension induced by spinal anaesthesia during pregnancy. Observation on gravid uterus of ewes. Journal of American Medical Association 1965;191:793-796

4. Gihan A G,Sherif A E. Prophylactic use of vasopressors for reduction of spinal anaesthesia induced hypotension during caesarian section Eg. J Anaesthesia. 2003:19:45-50

5. David W Cooper, Mark Carpenter. Foetal and maternal effects of phenylephrine and ephedrine during spinal anaesthesia for caesarian delivery.Anaesth.2002;97:15821590.

6. Ramanathan S, Grand G J. Vasopressor therapy for hypotension due to epidural anaesthesia for caesarian section, Acta.Anaesth.Scand.1988;32:559-565.

7. Moran B H, Perillo M, Laporta R F, Bader A M, Dutta S. Phenylephrine in the prevention of hypotension following spinal anaesthesia for caesarian delivery. Journal of clin. Anesthesia. 1991: 3: 301-305.

8. Chandrakal PG, Jennifer Malinowski, Aruna Tegginmath, Venketesh G, Suryanarayana Satheesh B,C Chandra. Vasopressor choice for hypotension in elective caesarian section: Ephedrine or Phenylephrine. Arch.MedSci2,April 2010

9. Ngan Kee W D, Khaw K S. Lee A, Ngan F, KarmakarM K, Gin T A. Randomised double blinded comparison of phenylephrine and ephedrine infusion combination to maintain blood pressure during spinal anaesthesia for caesarian delivery: The effect on foetal acid base status and haemodynamic control. Anaesth Analgesia 2008:107:1295-302.

10. Sahu D, Kothari D,Mehrothra A. A comparison of bolus Phenylephrine, Ephedrine and Mephenteramine for maintainence of arterial blood pressure during spinal anaesthesia for caesarian section A Clinical Study. IJA 2003: 47[2]:125-128.

11. A S Habeeb, A review of impact of phenylephrine administration on maternal haemodynamics and maternal and neonatal outcome in women undergoing caesarian section. Anaesthesia and Analgesia 2012 114[2]377-3902012.journals.www.com. 
12. Alfred Lee and R. S Atkinson. Synopsis of Anaesthesia. Resuscitation of Newborn page $649\left[6^{\text {th }}\right.$ edition $]$

13. Pharmacology and physiology in Anaesthesia practice, $3^{\text {rd }}$ edition 1999; pp. 264-272,Robert K Stoelting, LippencottRaven publishing.

14. Mohta M. et al, D.Agarwal M, L K Gupta. Potency of Mephenteramine for postspinal hypotension. Anaesthesia Intensive care 2009. PubMED. 2010 Jan:38[1]:208-9. 